\title{
Update on triple therapy for eradication of Helicobacter pylori: current status of the art
}

This article was published in the following Dove Press journal:

Clinical and Experimental Gastroenterology

15 September 2012

Number of times this article has been viewed

Riccardo Urgesi'

Rossella Cianci ${ }^{2}$

Maria Elena Riccioni ${ }^{3}$

'Gastroenterology and Endoscopy Unit, Viterbo, ${ }^{2}$ Institute of Internal Medicine, Catholic University of Rome, ${ }^{3}$ Digestive Endoscopy Unit, Catholic University of Rome,

Rome, Italy
Correspondence: Riccardo Urgesi Gastroenterology Unit,

Ospedale Belcolle, Viterbo, Strada Sammartinese I, 01100 Viterbo, Italy $\mathrm{Tel}+39347913081$ I

Fax +390761339313

Email riurgesi@tin.it
Abstract: With the rising prevalence of antimicrobial resistance, the treatment success of standard triple therapy has recently declined to unacceptable levels (ie, $80 \%$ or less). Following the failure of conventional triple therapy, novel eradication regimens have been developed including sequential therapy, concomitant quadruple therapy, hybrid (dual-concomitant) therapy, bismuth-containing quadruple therapy, and a therapy with administration of $\mathrm{N}$-acetylcysteine before a culture-guided antibiotic regimen. This article reviews the literature published on Helicobacter pylori eradication in the last year, focusing on the development of alternative strategies for first-, second-, and third-line rescue therapy for the eradication of H. pylori.

Keywords: sequential therapy, quadruple therapy, concomitant therapy, hybrid therapy, $\mathrm{N}$-acetylcysteine

\section{Introduction}

Helicobacter pylori infection is the main cause of gastritis, gastroduodenal ulcers, gastric adenocarcinoma, and mucosa-associated tissue lymphoma. Many patients attribute symptoms of dyspepsia to ulcers and believe that ulcers are caused by diet, stress, and lifestyle factors, but it is now clear that eradication of H. pylori is central to the management of this illness. Several large clinical trials and meta-analyses have shown that the eradication rate of the standard triple therapy has generally declined to unacceptable levels (ie, $80 \%$ or less) ) $^{1,2}$ and in some European countries the success rates are only $25 \%-60 \% .^{3,4}$ It is unclear why this fall in efficacy has occurred, but it may be related to the increasing incidence of clarithromycin-resistant strains of H. pylori. . $^{1,2,5,6}$

This article reviews the literature on special populations of $H$. pylori and their eradication using short-duration treatment regimens.

\section{First-line therapy: triple therapy}

The duration of treatment and adverse effects should be considered when selecting a therapy to eradicate $H$. pylori. The recommended duration of therapy for $H$. pylori eradication ranges from 7 to 14 days. The most widely recommended regimens are summarized in Table 1.

Over the past decade, it has been widely reported that $H$. pylori eradication treatment success rates are falling. A steady decline was observed in the number of patients achieving eradication with standard first-line triple therapy of two antibiotics and a proton pump inhibitor (PPI)..$^{7-9}$ It now appears that the first-line eradication 
Table I Regimens for Helicobacter pylori therapy

\begin{tabular}{|c|c|}
\hline \multicolumn{2}{|l|}{ First-line therapy } \\
\hline $\begin{array}{l}\text { Standard triple } \\
\text { therapy }\end{array}$ & $\begin{array}{l}\text { PPI (standard dose, bid), clarithromycin } \\
\text { (500 mg, bid) and amoxicillin ( } 1 \mathrm{~g} \text {, bid) for } 7-14 \text { days }\end{array}$ \\
\hline $\begin{array}{l}\text { Concomitant } \\
\text { therapy }\end{array}$ & $\begin{array}{l}\text { PPI (standard dose, bid), clarithromycin } \\
\text { (500 mg, bid), amoxicillin (I g, bid) and } \\
\text { metronidazole ( } 500 \mathrm{mg} \text {, bid) for 7-10 days }\end{array}$ \\
\hline Hybrid therapy & $\begin{array}{l}\text { 7-day dual therapy with a PPI (standard dose, } \\
\text { bid) and amoxicillin ( } \mathrm{I} \mathrm{g,} \mathrm{bid)} \mathrm{followed} \mathrm{by} \mathrm{a} \mathrm{7-day} \\
\text { quadruple therapy with a PPI (standard dose, } \\
\text { bid), amoxicillin ( } \mathrm{I} \mathrm{g,} \mathrm{bid),} \mathrm{clarithromycin} \\
\text { ( } 500 \mathrm{mg} \text {, bid), and metronidazole }(500 \mathrm{mg} \text {, bid) }\end{array}$ \\
\hline $\begin{array}{l}\text { Bismuth-containing } \\
\text { quadruple therapy }\end{array}$ & $\begin{array}{l}\text { PPI (standard dose, bid), bismuth (standard } \\
\text { dose, qid), tetracycline ( } 500 \mathrm{mg} \text {, qid), and } \\
\text { metronidazole ( } 250 \mathrm{mg} \text {, qid) for 10-14 days }\end{array}$ \\
\hline \multicolumn{2}{|c|}{ Second-line therapy } \\
\hline $\begin{array}{l}\text { Levofloxacin-based } \\
\text { triple therapy }\end{array}$ & $\begin{array}{l}\text { PPI (standard dose, bid), levofloxacin } \\
\text { (500 mg, qd), and amoxicillin (I g, bid) } \\
\text { for } 10 \text { days }\end{array}$ \\
\hline $\begin{array}{l}\text { Bismuth-containing } \\
\text { quadruple therapy }\end{array}$ & $\begin{array}{l}\text { PPI (standard dose, bid), bismuth (standard } \\
\text { dose, qid), tetracycline ( } 500 \mathrm{mg} \text {, qid), and } \\
\text { metronidazole ( } 500 \mathrm{mg} \text {, tid) for I0-14 days }\end{array}$ \\
\hline
\end{tabular}

Sequential therapy

Sequential therapy 5-day dual therapy with a PPI (standard dose, bid) and amoxicillin (I g, bid) followed by a 5-day triple therapy with a PPI (standard dose, bid), clarithromycin (500 mg, bid), and metronidazole (500 mg, bid)

Third-line therapy Culture-guided therapy

Levofloxacin-based quadruple therapy

I0-day quadruple therapy comprising a PPI (standard dose, bid), bismuth (standard dose, qid), and two antibiotics selected by antimicrobial sensitivity tests

PPI (standard dose, bid), bismuth (standard dose, qid), levofloxacin (500 mg, qd), and amoxicillin (500 mg, qid) for 10 days

Abbreviations: bid, twice daily; PPI, proton pump inhibitor; qd, once daily; qid, four times daily; tid, three times daily.

therapies most commonly used in everyday clinical practice (omeprazole-clarithromycin-amoxicillin) fall considerably short of the $80 \%$ intention-to-treat (ITT) eradication rates that are considered the minimal acceptable levels recommended in the Maastricht guidelines. ${ }^{10}$

The main reasons for eradication failure seem to be rapid metabolism of PPIs, antibiotic resistance, and poor patient compliance. ${ }^{1}$ However, the major cause of eradication failure appears to be clarithromycin resistance, ${ }^{6}$ with a systemic review showing that the rate of clarithromycin-resistant strains worldwide ranged from $49 \%$ in Spain to $1 \%$ in The Netherlands. ${ }^{11}$ In areas where clarithromycin resistance is $<10 \%$, it is still possible to employ a standard triple therapy to achieve a per-protocol eradication rate of $>90 \%$. However, standard triple therapies should be abandoned in areas with clarithromycin resistance $\geq 20 \%$ (ie, Spain, Turkey, Alaska,
China, and Japan) because the per-protocol eradication rates of standard therapies are often $<85 \%$ and the ITT eradication rates are usually $<80 \%$. ${ }^{6,12,13}$

Based on a large body of published clinical trials, ${ }^{14-17}$ it appears that a quinolone-based triple therapy can be effective in the first-line therapy of $H$. pylori infection. Levofloxacinbased triple therapy comprised of levofloxacin $(500 \mathrm{mg}$, once daily), amoxicillin ( $1 \mathrm{~g}$, twice daily [bid]), and a PPI (standard dose, bid). Levofloxacin may be used as a substitute for clarithromycin in either a standard triple or sequential regimen. A large study comparing the antibiotics in either regimen shows a clear advantage to levofloxacin in both combinations. Per-protocol cure rates for triple therapy were $66 \%$ for omeprazole-clarithromycin-amoxicillin compared with $83 \%$ for omeprazole-levofloxacin-amoxicillin, $81 \%$ for omeprazole-amoxicillin-clarithromycin-metronidazole, and $85 \%$ for omeprazole-amoxicillin-levofloxacin-metronidazole, with no difference in compliance rates or adverse events. ${ }^{14}$

Another study showed that the eradication rates of levofloxacin-based triple therapy ranged from $72 \%$ to $96 \%$, a regimen that might be considered in populations with clarithromycin resistance $>15 \%-20 \% .{ }^{15}$ However, a quinolone-based triple therapy is not generally recommended as first-line therapy at present due to concerns about the rising prevalence of quinolone-resistant strains in the firstand second-line anti-H. pylori therapies. ${ }^{16}$ The literature from Asia also seems to support levofloxacin as a good alternative first-line therapy. A study examining a triple regimen showed per-protocol eradication rates of $78 \%$ for standard clarithromycin-containing therapies compared with $83 \%$ for a levofloxacin-based regimen. ${ }^{16}$ Another study looked at whether combining clarithromycin and levofloxacin in the same regimen could be effective and found a $90 \%$ eradication rate for a combined clarithromycinlevofloxacin-esomeprazole regimen, compared with $85 \%$ for levofloxacin-amoxicillin-esomeprazole, and $79 \%$ for clarithromycin-amoxicillin-esomeprazole, with no difference in the incidence or severity of adverse events. ${ }^{17}$

The question remains, however, as to whether levofloxacin's best place is as first- or second-line therapy. A crossover study published in 2010 indicates that a clarithromycin-amoxicillin-lansoprazole regimen performs better than a levofloxacin-amoxicillin-lansoprazole regimen as first-line therapy ( $84 \%$ vs $74 \%$ ), but this is reversed in second-line therapy $(77 \%$ vs $60 \%) .{ }^{18}$ The eradication rate was significantly lower in the presence of levofloxacin resistance in the levofloxacin-amoxicillin-lansoprazole group $(50 \%$ vs $84 \%)$. 
Another role of levofloxacin may be in the treatment of patients with penicillin allergies. In a study of a levofloxacinbased regimen used in penicillin-allergic patients after omeprazole-clarithromycin-metronidazole had been unsuccessful, eradication rates of $73 \%$ were noted. ${ }^{19}$

\section{Second-line therapy: quadruple versus triple therapy}

The second-line therapy for patients for whom new firstline therapies fail to eradicate $H$. pylori remains unclear. The Maastricht III Consensus Report ${ }^{10}$ and the Second Asia-Pacific Consensus Guidelines ${ }^{20}$ for $\mathrm{H}$. pylori infection recommended a bismuth-containing quadruple therapy regimen comprising a PPI, bismuth, metronidazole, and tetracycline as second-line therapy. As in the case of clarithromycin, the prevalence of metronidazole-resistant strains, dose, and duration of rescue therapy seem to be important variables for the efficacy of this treatment. ${ }^{7,20}$ This rescue regimen fails in 5\%-63\% of patients, with an average eradication rate of $76 \%$ on the basis of a pooled analysis. ${ }^{21,22}$ In bismuth-containing quadruple regimens, the PPI should be prescribed in the usual dose twice per day, colloidal bismuth subcitrate $120 \mathrm{mg}$ four times per day, tetracycline $500 \mathrm{mg}$ four times per day, and metronidazole $500 \mathrm{mg}$ three times per day ${ }^{23} \mathrm{~A}$ report from Korea showed that the 2 -week bismuthcontaining quadruple therapy was more effective than the 1 -week treatment ( $83 \%$ vs $64 \%$ by ITT analysis). ${ }^{23}$

Two other studies with more than 100 patients have shown eradication rates of $>90 \%$ with this combination given for 10 days. ${ }^{24,25} \mathrm{~A}$ study has compared the efficacy of a 10-day bismuth-containing quadruple therapy (omeprazole-bismuthmetronidazole-tetracycline) with a 7-day conventional triple therapy (omeprazole-clarithromycin-amoxicillin). ${ }^{26}$ The data indicated that the former had a higher eradication rate than the latter ( $93 \%$ vs $70 \%$ by per-protocol analysis). The optimal treatment duration of bismuth-containing quadruple therapy remains unclear, but a 10-14 day treatment is most commonly employed in clinical practice. ${ }^{27}$ A meta-analysis compared the effectiveness of a 10-day regimen of levofloxacin-based triple therapy versus a 7-day bismuth-based quadruple therapy and demonstrated the superiority of the former. ${ }^{28}$ Another meta-analysis demonstrated a borderline significance of higher $H$. pylori cure rates with levofloxacin-based triple regimens compared with quadruple therapies ( $81 \%$ vs $70 \%)$. Additionally, the study revealed fewer adverse effects with levofloxacin than with quadruple regimens ( $19 \%$ vs $44 \%){ }^{29}$

In another study, the efficacy and safety of a 10-day novel, single-capsule, bismuth-based quadruple therapy (bismuth-metronidazole-tetracycline-omeprazole) as first-line therapy was assessed. This multicenter study showed an eradication rate of $80 \%$ in the quadruple therapy group versus $55 \%$ for the standard 7-day triple-therapy group. Two randomized controlled trials from Taiwan and Hong Kong have shown that levofloxacin-based triple therapy was comparable to quadruple therapy in eradication efficacy as second-line therapy and a recent study has shown that a levofloxacinbased triple therapy with lansoprazole ( $30 \mathrm{mg}$, bid), levofloxacin $(250 \mathrm{mg}$, bid), and amoxicillin (1 g, bid) achieved a high eradication rate in patients who failed to clear H. pylori with sequential therapy. ${ }^{30-32}$

\section{Sequential therapy: between first and second line?}

The primary goal of the sequential regimen is to overcome clarithromycin resistance. Several studies have shown that a novel 10-day sequential therapy can achieve success rates of $90 \%-94 \%{ }^{33,34}$ The regimen consists of a 5-day dual therapy with a PPI (standard dose, bid) and amoxicillin (1 g, bid), followed by a 5-day triple therapy with a PPI (standard dose, bid), clarithromycin (500 mg, bid), and metronidazole (500 mg, bid). One study from Thailand reported a 95\% eradication rate for a 10 -day sequential therapy, ${ }^{35}$ while a study from Turkey, where eradication rates are low, showed $78 \%$ eradication for sequential therapy versus $53 \%$ for standard triple therapy based on a per-protocol analysis. ${ }^{36}$ In China, a comparative study showed eradication rates of $83 \%$ for bismuth-based quadruple therapy and $81 \%$ for standard triple therapy, with an eradication rate of $89 \%$ for sequential therapy. ${ }^{37}$

A systematic review that identified 13 trials evaluating 3271 patients showed that sequential therapy achieved a $12 \%$ better absolute eradication rate than the standard triple therapy..$^{38} \mathrm{~A}$ randomized, double-blind, placebo-controlled trial demonstrated that the per-protocol eradication rates of sequential therapy and standard triple therapy for clarithromycin-resistant strains were $89 \%$ and $29 \%$, respectively. ${ }^{33}$ Another study has shown that the eradication rate in naive patients treated with sequential therapy was significantly higher than in those treated with conventional triple therapy $(92.5 \%$ vs $73.7 \%, P=0.0015$, odds ratio $=4.39$, [95\% confidence interval (CI) 1.66 to 11.58$]) .{ }^{39} \mathrm{~A}$ recent trial in Korea found that the per-protocol eradication rates of sequential therapy versus standard triple therapy were $86 \%$ and $77 \%$, respectively. ${ }^{40}$ It should be noted, however, that most of the studies concerning sequential therapies were conducted in Italy and there is a clear need for well-designed 
randomized trials from other countries to confirm the real advantages of this regimen.

\section{Third-line therapy}

The Maastricht III Consensus Report recommended the use of bacterial culture with antimicrobial sensitivity tests to select antibiotics for third-line regimens, but it has been reported that the sensitivity of culture is $<60 \%{ }^{7,41}$ Additionally, in vitro antimicrobial sensitivity does not necessarily lead to eradication in vivo, or vice versa. Cammarota et al treated 94 patients with a culture-guided third-line regimen: 89 patients received a 1-week quadruple regimen including omeprazole, bismuth, doxycycline, and amoxicillin, and five patients received a 1-week triple regimen containing omeprazole, amoxicillin, and levofloxacin or clarithromycin. Overall, H. pylori eradication was obtained in $90 \%$ of subjects treated with the culture-guided therapy. ${ }^{42}$

Another proposed alternative therapy in the multiresistant and clarithromycin-resistant forms is a quadruple therapy called "concomitant" therapy. ${ }^{43}$ This is a four-drug regimen containing a PPI (standard dose, bid), clarithromycin (500 mg, bid), amoxicillin ( $1 \mathrm{~g}$, bid), and metronidazole (500 mg, bid), which are all given for the entire duration of therapy. This regimen is intended to reduce the complexity associated with sequential therapy, as the patient takes all three antibiotics for the entire 10-day duration. When compared with standard triple therapy in a meta-analysis, concomitant therapy had an ITT eradication rate of $90 \%$, superior to standard triple therapy, with a pooled odds ratio of $2.86 .{ }^{43}$ When compared with the sequential regimen, concomitant administration of the same drugs provides similar results in terms of efficacy and safety. A head-to-head noninferiority trial of 10-day sequential and 10-day concomitant therapy showed that they were equivalent $(93.1 \%$ vs $93.0 \%$ by per-protocol analysis). ${ }^{44}$

Hsu et al reported a "hybrid (dual-concomitant) therapy" consisting of a dual therapy with a PPI (standard dose, bid) and amoxicillin ( $1 \mathrm{~g}$, bid) for 7 days followed by a concomitant quadruple therapy with a PPI (bid), amoxicillin (1 g, bid), clarithromycin (500 mg, bid), and metronidazole (500 mg, bid) for 7 days. ${ }^{45}$ This regimen extends the duration of amoxicillin treatment to 14 days and concomitantly employs three antibiotics in the last 7 days of the treatment course. In 117 treated subjects, the therapy provided excellent eradication rates of $99 \%$ and $97 \%$ according to per-protocol and ITT analysis, respectively. It is important to note that the new therapy has a high efficacy in the treatment of H. pylori strains harboring dual resistance to clarithromycin and metronidazole. Further studies in populations with different levels of prevalence of clarithromycin and metronidazole resistance are needed to assess the efficacy of the new regimen.

A novel regimen has been proposed in an open-label, randomized controlled trial ${ }^{46}$ involving 40 subjects with a history of at least four $H$. pylori eradication failures. Subjects were randomly assigned to receive (group A) or not (group B) $\mathrm{N}$-acetylcysteine before a culture-guided antibiotic regimen. H. pylori was eradicated in 13/20 (both per-protocol and ITT analyses, 65\%; 95\% CI: 44\%-86\%) group A participants and 4/20 (both per-protocol and ITT analyses, 20\%; 95\% CI: 3\%-37\%) group B participants $(P<0.01)$. Biofilms persisted only in participants unsuccessfully treated. H. pylori genotypes did not influence treatment outcome.

$\mathrm{N}$-acetylcysteine pretreatment before a culture-guided antibiotic regimen is effective in overcoming $H$. pylori antibiotic resistance. ${ }^{46}$ Two other therapeutic regimens involving a proposed use of rifabutin (150 mg, bid), amoxicillin (1 g, bid), and omeprazole (20 mg, bid) for 14 days and the other the use of lansoprazole (30 mg, bid), tripotassium dicitratobismuthate (240 mg, bid), furazolidone (200 mg, bid), and tetracycline ( $1 \mathrm{~g}$, bid) for 7 days. ${ }^{47,48}$ In the first regime, the per-protocol and ITT eradication was achieved in 11/14 patients $(79 \%)$, while in the second regime the eradication rate was $90 \%$ by both ITT and per-protocol analysis.

Table 2 lists the recommended regimens in countries with clarithromycin resistance.

\section{A role for probiotics?}

Some studies have recently evaluated the role of the Saccharomyces boulardii as a coadjutant in the eradication of $H$. pylori and in the prevention of the secondary effects of antibiotic therapy. A meta-analysis showed that supplementation with $S$. boulardii significantly increased the $H$. pylori eradication rate and reduced the risk of overall $H$. pylori therapy-related adverse effects. ${ }^{49}$ In a cohort of patients in Korea who received $S$. boulardii for 4 weeks during and after a 1-week course of standard triple therapy, eradication rates were $10 \%$ higher than for those who did not receive the supplement..$^{50}$ Other studies in which Bifidobacterium spp. and Lactobacillus acidophilus have been administered revealed no significant difference in eradication rates in patients who were infected with strains susceptible to both antibiotics and who were treated with standard triple therapy. ${ }^{51,52}$ Further studies will be necessary to clarify the exact role of the probiotics in the eradication treatment. 
Table 2 Recommended regimens in countries with clarithromycin resistance

\begin{tabular}{|c|c|c|c|c|c|}
\hline \multirow[t]{2}{*}{ Regimen } & \multirow[t]{2}{*}{ Country } & \multicolumn{3}{|l|}{ ITT } & \multirow{2}{*}{$\begin{array}{l}\% \text { clarithromycin } \\
\text { resistance }\end{array}$} \\
\hline & & $\begin{array}{l}\text { Eradication } \\
\text { rate } 14 \text { days }\end{array}$ & $\begin{array}{l}\text { Eradication } \\
\text { rate } 7 \text { days }\end{array}$ & $\begin{array}{l}\text { Eradication } \\
\text { rate } 10 \text { days }\end{array}$ & \\
\hline PAC & Italy & $57 \%-80 \%$ & $82 \%$ & $70 \%$ & $\geq 20 \%$ \\
\hline PAM & Italy & $52 \%$ & - & $56 \%$ & $\geq 20 \%$ \\
\hline PAC & Spain & $86 \%$ & - & - & $\geq 20 \%$ \\
\hline PAC & Korea & $71 \%$ & - & $76 \%$ & $\leq 20 \%$ \\
\hline PCL & Italy & $87 \%$ & - & - & $\geq 20 \%$ \\
\hline BAL & Spain & - & $84 \%$ & - & $\geq 20 \%$ \\
\hline PAC & China & $81 \%$ & - & - & $\geq 20 \%$ \\
\hline PBMT & Italy & - & $91 \%$ & - & $\geq 20 \%$ \\
\hline PBMT & Spain & $89 \%$ & - & - & $\geq 20 \%$ \\
\hline PBMT & China & $83 \%$ & - & - & $\geq 20 \%$ \\
\hline PAMC & Taiwan & - & $93 \%$ & - & $\geq 20 \%$ \\
\hline SeTrT & Italy & - & $92 \%-94 \%$ & - & $\geq 20 \%$ \\
\hline SeTrT & China & - & $89 \%$ & - & $\geq 20 \%$ \\
\hline SeTrT & Thailand & - & $95 \%$ & - & $\leq 20 \%$ \\
\hline SeTrT & Korea & - & $86 \%$ & - & $\leq 20 \%$ \\
\hline
\end{tabular}

Abbreviations: P, proton pump inhibitor; A, amoxicillin; C, clarithromycin; M, metronidazole; L, levofloxacin; B, ranitidine bismuth citrate; M, metronidazole; T, tetracycline; ITT, intention to treat; SeTrT, sequential triple therapy.

\section{Conclusion}

The constant development of new antibiotic resistances suggests that future treatment will need to be individualized on the basis of host polymorphisms, antibiotic resistance, demographic factors, and, occasionally, comorbidity. Sequential therapy could be an alternative to the conventional triple therapy as first-line therapy. If the standard triple therapy or sequential therapy should fail, a levofloxacin-based triple therapy or a bismuth-containing quadruple therapy can be employed as rescue treatment. A levofloxacin-based triple therapy is an acceptable salvage treatment and an alternative to metronidazole. A culture-guided third-line therapy has been recommended, but if antimicrobial sensitivity data are unavailable, an empirical triple or quadruple therapy can be employed.

While there are a large number of emerging therapies, no consensus has been reached on these, and no "magic bullet" has emerged for $H$. pylori eradication. The authors of this review believe that, at present, the optimal approach in the treatment of patients with $H$. pylori infection is to use whichever protocol the literature indicates has the highest eradication rates and shorter duration. The type of regimen chosen will vary depending on the level of clarithromycin resistance in the country concerned, so each country should periodically publish data on the outcomes of eradication regimens and the antibiotic resistance rates to facilitate the appropriate therapeutic choice.

\section{Disclosure}

The authors report no conflicts of interest in this work.

\section{References}

1. Graham DY, Fischbach L. Helicobacter pylori treatment in the era of increasing antibiotic resistance. Gut. 2010;59(8):1143-1153.

2. Gisbert JP, Pajares R, Pajares JM. Evolution of Helicobacter pylori therapy from a meta-analytical perspective. Helicobacter. 2007;12 Suppl 2:50-58.

3. Gumurdulu Y, Serin E, Ozer B, et al. Low eradication rate of Helicobacter pylori with triple 7-14 days and quadruple therapy in Turkey. World J Gastroenterol. 2004;10(5):668-671.

4. Bigard MA, Delchier JC, Riachi G, Thibault P, Barthelemy P. One-week triple therapy using omeprazole, amoxycillin and clarithromycin for the eradication of Helicobacter pylori in patients with non-ulcer dyspepsia: influence of dosage of omeprazole and clarithromycin. Aliment Pharmacol Ther. 1998;12(4):383-388.

5. Cianci R, Montalto M, Pandolfi F, Gasbarrini GB, Cammarota G. Third-line rescue therapy for Helicobacter pylori infection. World $J$ Gastroenterol. 2006;12(15):2313-2319.

6. Mégraud F. H pylori antibiotic resistance: prevalence, importance, and advances in testing. Gut. 2004;53(9):1374-1384.

7. Bytzer P, Dahlerup JF, Eriksen JR, Jarbøl DE, Rosenstock S, Wildt S; Danish Society for Gastroenterology. Diagnosis and treatment of Helicobacter pylori infection. Dan Med Bull. 2011;58(4):C4271.

8. Gisbert JP, Pajares JM. Treatment of Helicobacter pylori infection: the past and the future. Eur J Intern Med. 2010;21(5):357-359.

9. Paoluzi OA, Visconti E, Andrei F, et al. Ten and eight-day sequential therapy in comparison to standard triple therapy for eradicating Helicobacter pylori infection: a randomized controlled study on efficacy and tolerability. J Clin Gastroenterol. 2010;44(4): 261-266.

10. Malfertheiner P, Megraud F, O'Morain C, et al. Current concepts in the management of Helicobacter pylori infection: the Maastricht III Consensus Report. Gut. 2007;56(6):772-781.

11. De Francesco V, Giorgio F, Hassan C, et al. Worldwide H. pylori antibiotic resistance: a systematic review. J Gastrointestin Liver Dis. 2010;19(4):409-414.

12. Rimbara E, Fischbach LA, Graham DY. Optimal therapy for Helicobacter pylori infections. Nat Rev Gastroenterol Hepatol. 2011; 8(2):79-88.

13. Graham DY, Lu H, Yamaoka Y. Therapy for Helicobacter pylori infection can be improved: sequential therapy and beyond. Drugs. 2008;68(6):725-736. 
14. Molina-Infante J, Perez-Gallardo B, Fernandez-Bermejo M, et al. Clinical trial: clarithromycin vs levofloxacin in first-line triple and sequential regimens for Helicobacter pylori eradication. Aliment Pharmacol Ther. 2010;31(10):1077-1084.

15. Berning M, Krasz S, Miehlke S. Should quinolones come first in Helicobacter pylori therapy? Therap Adv Gastroenterol. 2011;4(2): 103-114.

16. Cheng H, Hu FL, Zhang GX, et al. Levofloxacin-based triple therapy for first-line Helicobacter pylori eradication treatment: a multi-central, randomized, controlled clinical study. Zhonghua Yi Xue Za Zhi. 2010; 90(2):79-82. Chinese

17. Assem M, El Azab G, Rasheed MA, Abdelfatah M, Shastery M. Efficacy and safety of Levofloxacin, Clarithromycin and Esomeprazol as first line triple therapy for Helicobacter pylori eradication in Middle East. Prospective, randomized, blind, comparative, multicenter study. Eur J Intern Med. 2010;21(4):310-314.

18. Liou JM, Lin JT, Chang CY, et al. Levofloxacin-based and clarithromycin-based triple therapies as first-line and second-line treatments for Helicobacter pylori infection: a randomised comparative trial with crossover design. Gut. 2010;59(5):572-578.

19. Gisbert JP, Pérez-Aisa A, Castro-Fernández M, et al. Helicobacter pylori first-line treatment and rescue option containing levofloxacin in patients allergic to penicillin. Dig Liver Dis. 2010;42(4): 287-290.

20. Fock KM, Katelaris P, Sugano K, et al. Second Asia-Pacific Consensus Guidelines for Helicobacter pylori infection. $J$ Gastroenterol Hepatol. 2009;24(10):1587-1600.

21. Wu DC, Hsu PI, Tseng HH, et al. Helicobacter pylori infection: a randomized, controlled study comparing 2 rescue therapies after failure of standard triple therapies. Medicine (Baltimore). 2011;90(3): $180-185$.

22. Gisbert JP. "Rescue" regimens after Helicobacter pylori treatment failure. World J Gastroenterol. 2008;14(35):5385-5402.

23. Lee BH, Kim N, Hwang TJ, et al. Bismuth-containing quadruple therapy as second-line treatment for Helicobacter pylori infection: effect of treatment duration and antibiotic resistance on the eradication rate in Korea. Helicobacter. 2010;15(1):38-45.

24. O'Morain C, Borody T, Farley A, et al. Efficacy and safety of singletriple capsules of bismuth biskalcitrate, metronidazole and tetracycline, given with omeprazole, for the eradication of Helicobacter pylori: an international multicentre study. Aliment Pharmacol Ther. 2003;17(3): 415-420.

25. Laine L, Hunt R, El-Zimaity H, Nguyen B, Osato M, Spénard J. Bismuth-based quadruple therapy using a single capsule of bismuth biskalcitrate, metronidazole, and tetracycline given with omeprazole versus omeprazole, amoxicillin, and clarithromycin for eradication of Helicobacter pylori in duodenal ulcer patients: a prospective, randomized, multicenter, North American trial. Am J Gastroenterol. 2003; 98(3):562-567.

26. Malfertheiner P, Bazzoli F, Delchier JC, et al. Helicobacter pylori eradication with a capsule containing bismuth subcitrate potassium, metronidazole, and tetracycline given with omeprazole versus clarithromycin-based triple therapy: a randomised, open-label, non-inferiority, phase 3 trial. Lancet. 2011;377(9769): 905-913.

27. Chey WD, Wong BC. American College of Gastroenterology guideline on the management of Helicobacter pylori infection. Am J Gastroenterol. 2007;102(8):1808-1825.

28. Saad RJ, Schoenfeld P, Kim HM, Chey WD. Levofloxacin-based triple therapy versus bismuth-based quadruple therapy for persistent Helicobacter pylori infection: a meta-analysis. Am J Gastroenterol. 2006;101(3):488-496.

29. Gisbert JP, Morena F. Systematic review and meta-analysis: levofloxacin-based rescue regimens after Helicobacter pylori treatment failure. Aliment Pharmacol Ther. 2006;23(1):35-44.
30. Kuo CH, Hu HM, Kuo FC, et al. Efficacy of levofloxacin-based rescue therapy for Helicobacter pylori infection after standard triple therapy: a randomized controlled trial. J Antimicrob Chemother. 2009;63(5): 1017-1024.

31. Wong WM, Gu Q, Chu KM, et al. Lansoprazole, levofloxacin and amoxicillin triple therapy vs quadruple therapy as second-line treatment of resistant Helicobacter pylori infection. Aliment Pharmacol Ther. 2006;23(3):421-427.

32. Pontone S, Standoli M, Angelini R, Pontone P. Efficacy of H. pylori eradication with a sequential regimen followed by rescue therapy in clinical practice. Dig Liver Dis. 2010;42(8):541-543.

33. Vaira D, Zullo A, Vakil N, et al. Sequential therapy versus standard triple-drug therapy for Helicobacter pylori eradication: a randomized trial. Ann Intern Med. 2007;146(8):556-563.

34. Hsu PI, Wu DC, Wu JY, Graham DY. Is there a benefit to extending the duration of Helicobacter pylori sequential therapy to 14 days? Helicobacter. 2011;16(2):146-152.

35. Sirimontaporn N, Thong-Ngam D, Tumwasorn S, Mahachai V. Ten-day sequential therapy of Helicobacter pylori infection in Thailand. Am J Gastroenterol. 2010;105(5):1071-1075.

36. Nadir I, Yonem O, Ozin Y, Kilic ZM, Sezgin O. Comparison of two different treatment protocols in Helicobacter pylori eradication. South Med J. 2011;104(2):102-105.

37. Gao XZ, Qiao XL, Song WC, Wang XF, Liu F. Standard triple, bismuth pectin quadruple and sequential therapies for Helicobacter pylori eradication. World J Gastroenterol. 2010;16(34):4357-4362.

38. Gatta L, Vakil N, Leandro G, Di Mario F, Vaira D. Sequential therapy or triple therapy for Helicobacter pylori infection: systematic review and meta-analysis of randomized controlled trials in adults and children. Am J Gastroenterol. 2009;104(12):3069-3079.

39. Urgesi R, Pelecca G, Cianci R, et al. Helicobacter pylori infection: is sequential therapy superior to standard triple therapy? Single centre Italian study in naïve and non naïve patients to treatment. Can $J$ Gastroenterol. 2011;25(6):315-318.

40. Choi WH, Park DI, Oh SJ, et al. Effectiveness of 10 day-sequential therapy for Helicobacter pylori eradication in Korea. Korean $J$ Gastroenterol. 2008;51(5):280-284. Korean.

41. Savarino V, Zentilin P, Pivari M, et al. The impact of antibiotic resistance on the efficacy of three 7-day regimens against Helicobacter pylori. Aliment Pharmacol Ther. 2000;14(7):893-900.

42. Cammarota G, Martino A, Pirozzi G, et al. High efficacy of 1-week doxycycline- and amoxicillin-based quadruple regimen in a cultureguided, third-line treatment approach for Helicobacter pylori infection. Aliment Pharmacol Ther. 2004;19(7):789-795.

43. Essa AS, Kramer JR, Graham DY, Treiber G. Meta-analysis: four-drug, three-antibiotic, non-bismuth-containing "concomitant therapy" versus triple therapy for Helicobacter pylori eradication. Helicobacter. 2009; 14(2):109-118

44. Wu DC, Hsu PI, Wu JY, et al. Sequential and concomitant therapy with four drugs is equally effective for eradication of $\mathrm{H}$ pylori infection. Clin Gastroenterol Hepatol. 2010;8(1):36-41.

45. Hsu PI, Wu DC, Wu JY, Graham DY. Modified sequential Helicobacter pylori therapy: proton pump inhibitor and amoxicillin for 14 days with clarithromycin and metronidazole added as a quadruple (hybrid) therapy for the final 7 days. Helicobacter. 2011;16(2): 139-145.

46. Cammarota G, Branca G, Ardito F, et al. Biofilm demolition and antibiotic treatment to eradicate resistant Helicobacter pylori: a clinical trial. Clin Gastroenterol Hepatol. 2010;8(9):817-820.

47. Gisbert JP, Calvet X, Bujanda L, Marcos S, Gisbert JL, Pajares JM. 'Rescue' therapy with rifabutin after multiple Helicobacter pylori treatment failures. Helicobacter. 2003;8(2):90-94.

48. Treiber G, Ammon S, Malfertheiner P, Klotz U. Impact of furazolidonebased quadruple therapy for eradication of Helicobacter pylori after previous treatment failures. Helicobacter. 2002;7(4):225-231. 
49. Szajewska H, Horvath A, Piwowarczyk A. Meta-analysis: the effects of Saccharomyces boulardii supplementation on Helicobacter pylori eradication rates and side effects during treatment. Aliment Pharmacol Ther. 2010;32(9):1069-1079.

50. Song MJ, Park DI, Park JH, et al. The effect of probiotics and mucoprotective agents on PPI-based triple therapy for eradication of Helicobacter pylori. Helicobacter. 2010;15(3):206-213.
51. Yaşar B, Abut E, Kayadıbı H, et al. Efficacy of probiotics in Helicobacter pylori eradication therapy. Turk J Gastroenterol. 2010;21(3): 212-217.

52. da Silva Medeiros JA, Gonçalves TM, Boyanova L, et al. Evaluation of Helicobacter pylori eradication by triple therapy plus Lactobacillus acidophilus compared to triple therapy alone. Eur J Clin Microbiol Infect Dis. 2011;30(4):555-559.

\section{Publish your work in this journal}

Clinical and Experimental Gastroenterology is an international, peerreviewed, open access journal, publishing all aspects of gastroenterology in the clinic and laboratory, including: Pathology, pathophysiology of gastrointestinal disease; Investigation and treatment of gastointestinal disease; Pharmacology of drugs used in the alimentary tract;
Immunology/genetics/genomics related to gastrointestinal disease. This journal is indexed on CAS. The manuscript management system is completely online and includes a very quick and fair peer-review system. Visit http://www.dovepress.com/testimonials.php to read real quotes from published authors.

Submit your manuscript here: http://www.dovepress.com/clinical-and-experimental-gastroenterology-journal 